
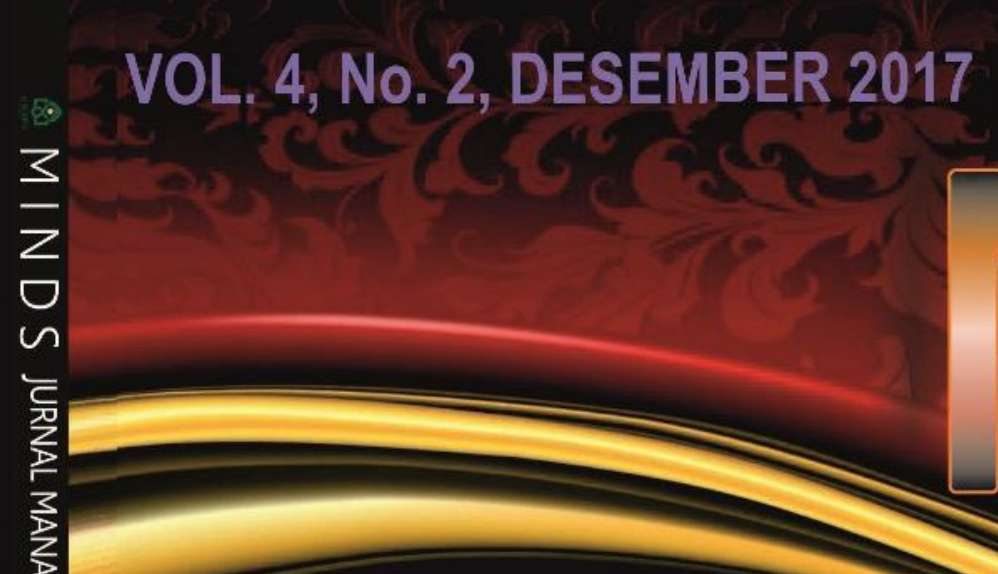

ShI

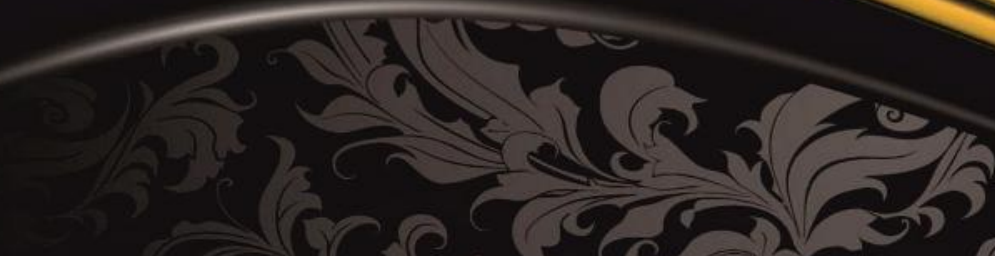

(ब)
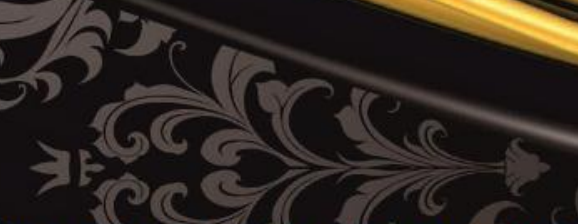

(C)

IDENTIFIKASI GAYA KEPEMIMPINAN PADA ORGANISASI RELAWAN PENANGGULANGAN BENCANA DI JAWA TIMUR

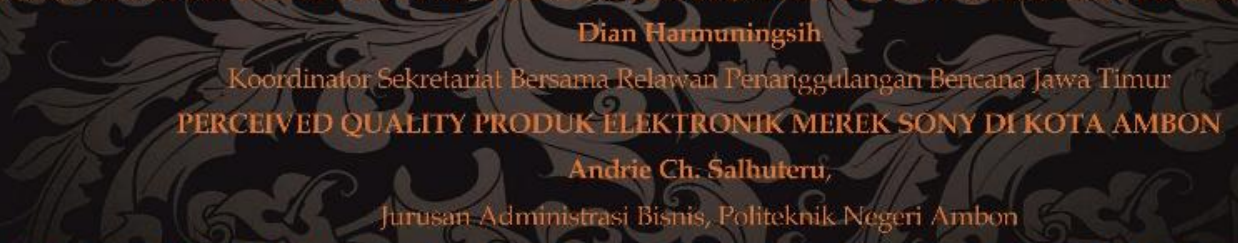

PENGARUH PROFITABILITAS, UIKUIDITAS, LEVERAGE, DAN FIRM SIZE TERHADAP KEBIJAKAN DIVIDEN PERUSAHAAN

$$
\begin{aligned}
& \text { DI INDEKS JII, PERIODE 2011-2015 } \\
& \text { Rika Dwi Ayu Parmitasari \& Hasrianto, }
\end{aligned}
$$

Jurusan Manajemen Fakultas Ekonomi dan Bisnis Islam, UIN Alauddin Makassar

FAKTOR YANG MEMENGARUHI KEPUASAN NASABAH BANK MUAMALAT CABANG AMBON

$$
\text { Gilman Pary, }
$$

Institut Agama Islam Negeri Ambon,

PENGARUH ATRIBUT PRODUK DAN PERILAKU PENCARIAN VARIASI TERHADAP PERILAKU MAHASISWA BERPINDAH MEREK PONSEL PADA FAKULTAS EKONOMI DAN BISNIS ISLAM Jusmiati \& Ahmad Efendi,

Jurusan Manajemen, Fakultas Ekonomi dan Bisnis Islam, UIN Alauddin Makassar

PENGARUH KUALITAS LAYANAN TERHADAP KEPUASAN PELANGGAN RUTE DOMESTIK GARUDA INDONESIA DI KOTA AMBON Saul Ronald Jacob Saleky,

Jurusan Administrasi Bisnis, Politeknik Negeri Ambon

PENGARUH STRES KERJA DAN IKLIM ORGANISASI TERHADAP TURNOVER KARYAWAN

$$
\text { Ludy Sapulette, }
$$

Jurusan Administrasi Bisnis, Politeknik Negeri Ambon

PENGARUH PEMBERDAYAAN DAN BUDAYA ORGANISASI TERHADAP PROFESIONALISME DOSEN

Ady Andardinata,

STIE Tri Dharma Nusantara

PENGARUH CSR, FIRM SIZE DAN INTEREST-BASED DEBT TERHADAP NILAI PERUSAHAAN PADA PERUSAHAAN MANUFAKTUR DI INDEKS JII, PERIODE 2010-2016

Wahidah Abdullah, Alim Syariati, \& Reskianti hamid

Fakultas Ekonomi dan Bisnis Islam, UNN Alauddin Makassar

ANALISIS DIMENSI KUALITAS PELAYANAN TERHADAP KEPUASAAN PASIEN PADA RSUD SYEKH YUSUF SUNGGUMINASA Asdi,

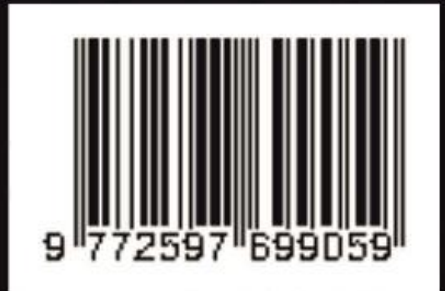

FEB, Lniversitas Muhammadiyah Makassar 
[Type text]

\section{KATA PENGANTAR}

Assalamualaikum WR. WB.

Puja dan puji syukur mari kita panjatkan ke hadirat Allah SWT, karena atas berkah dan karunia-Nya, maka Jurnal Manajemen dan Inspirasi (MINDS), Jurusan Manajemen, Fakultas Ekonomi dan Bisnis Islam, UIN Alauddin Makassar ini dapat diselesaikan. Salam dan shalawat kita haturkan kepada Nabi Muhammad SAW, sang pelita di tengah kejumudan dan kejahiliyahan, serta sumber informasi dan inspirasi yang terpercaya, al-Amiin. Terima kasih kami sampaikan kepada seluruh pihak yang terlibat dalam penyusunan jurnal Minds dari awal hingga akhir yang tidak dapat kami sebutkan satu persatu.

Adapun jurnal Minds merupakan titik kulminasi perwujudan kemampuan menulis tenaga pendidik yang berada di intra Fakultas maupun luar universitas. Tulisan akademik yang diharapkan menjadi contoh nyata jawaban dari berbagai fenomena empiris yang relevan dari sisi keilmuan Manajemen. Edisi kali ini, yaitu Vol. 4, No.2, 2017, mengupayakan adanya pengembangan dari sisi kualitas tulisan maupun sebaran wilayah penulis. Upaya ini diharapkan akan mendorong terciptanya proses yang lebih terukur baik dari penulis, mitra bestari, maupun penyunting, sehingga peningkatan kualitas publikasi ilmiah dapat diharapkan sebagai keluaran yang pasti.

Seiring dengan penerbitan jurnal ini, maka mewakili tim publikasi, saya menyampaikan rasa terima kasih yang sebesar-besarnya untuk seluruh penulis yang berpartisipasi dalam edisi kali ini, dan kepada para pembaca yang telah berkenan meluangkan waktunya untuk menelaah tulisan-tulisan yang termuat pada edisi kali ini.

Wassalamualaikum WR.WB.

Manajer Jurnal,

Dr. Alim Syariati, SE., M.Si. 


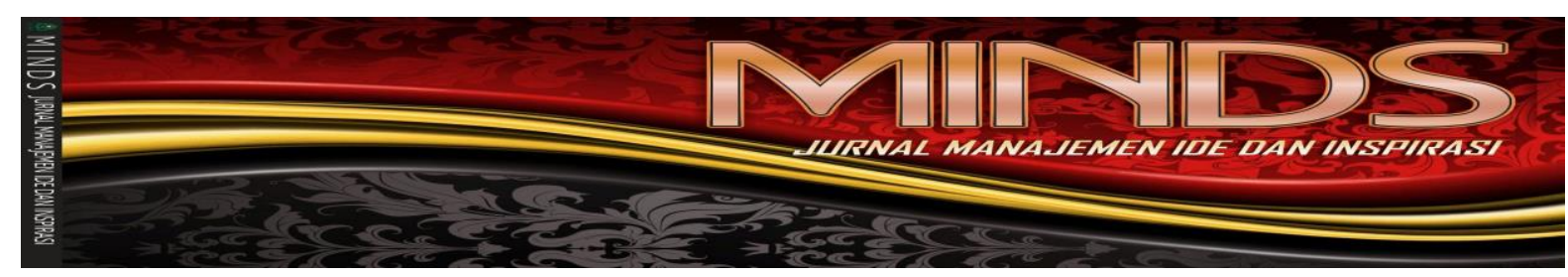

\section{DAFTAR ISI}

IDENTIFIKASI GAYA KEPEMIMPINAN PADA ORGANISASI

RELAWAN PENANGGULANGAN BENCANA DI JAWA TIMUR......

Dian Harmuningsih

Koordinator Sekretariat Bersama Relawan Penanggulangan Bencana Jawa Timur

PERCEIVED QUALITY PRODUK ELEKTRONIK MEREK SONY

DI KOTA AMBON

Andrie Ch. Salhuteru,

Jurusan Administrasi Bisnis, Politeknik Negeri Ambon

PENGARUH PROFITABILITAS, LIKUIDITAS, LEVERAGE, DAN

UKURAN PERUSAHAAN TERHADAP KEBIJAKAN DIVIDEN

SAHAM-SAHAM YANG TERDAFTAR PADA

JAKARTA ISLAMIC INDEX (JII) PERIODE TAHUN 2011-2015........

Rika Dwi Ayu Parmitasari \& Hasrianto,

Jurusan Manajemen Fakultas Ekonomi dan Bisnis Islam, UIN Alauddin Makassar

FAKTOR YANG MEMENGARUHI KEPUASAN NASABAH

BANK MUAMALAT CABANG AMBON

Gilman Pary,

Institut Agama Islam Negeri Ambon,

PENGARUH ATRIBUT PRODUK DAN PERILAKU PENCARIAN

VARIASI TERHADAP PERILAKU MAHASISWA BERPINDAH MEREK

PONSEL PADA FAKULTAS EKONOMI DAN BISNIS ISLAM............

Jusmiati \& Ahmad Efendi,

Jurusan Manajemen, Fakultas Ekonomi dan Bisnis Islam, UIN Alauddin Makassar

PENGARUH KUALITAS LAYANAN TERHADAP KEPUASAN PELANGGAN RUTE DOMESTIK GARUDA INDONESIA DI KOTA AMBON

Saul Ronald Jacob Saleky,

Jurusan Administrasi Bisnis, Politeknik Negeri Ambon

PENGARUH STRES KERJA DAN IKLIM ORGANISASI TERHADAP

TURNOVER INTENTION

Ludy Sapulette,

Jurusan Administrasi Bisnis, Politeknik Negeri Ambon

PENGARUH PEMBERDAYAAN DAN BUDAYA ORGANISASI

TERHADAP PROFESIONALISME DOSEN.

Ady Andardinata,

STIE Tri Dharma Nusantara 
PENGARUH CORPORATE SOCIAL RESPONSIBILITY (CSR), UKURAN PERUSAHAAN DAN INTEREST BASED DEBT (IBD) TERHADAP NILAI PERUSAHAAN PADA PERUSAHAAN MANUFAKTUR (YANG TERDAFTAR DI JAKARTA ISLAMIC INDEX PERIODE 2010-2016)..... Wahidah Abdullah, Alim Syariati, \& Reskianti hamid

Fakultas Ekonomi dan Bisnis Islam, UIN Alauddin Makassar

ANALISIS DIMENSI KUALITAS PELAYANAN TERHADAP KEPUASAAN PASIEN PADA RSUD SYEKH YUSUF SUNGGUMINASA

Asdi, FEB,

Universitas Muhammadiyah Makassar 


\title{
ANALISIS DIMENSI KUALITAS PELAYANAN TERHADAP KEPUASAAN PASIEN PADA RSUD SYEKH YUSUF SUNGGUMINASA KABUPATEN GOWA
}

\begin{abstract}
Asdi $^{*}$
Abstract.

Service quality is assessment base for impatient obtains health service activities at hospital. This research aim (1) how know the applying of dimension service quality consisted by tangible, empathy, reliability, responsiveness, and assurance has relationship with satisfaction of patient, and (2) dimension quality of which service gives the relation of dominance to satisfaction of patient. This research executed in Syekh Yusuf Public Hospital Sungguminasa Gowa Sub-Province, by getting sample 300 patient as responder. Data collecting using questionnaire and data processing applies analytical technique Chi-Square, Coefficient Contingence, and index of relation power. Result of research indicates that (1) either in simultan and also partially dimension service quality consisted of by tangible, empathy, reliability, responsiveness, and assurance has the relation of signifikan with satisfaction of patient, and (2) evidence dimension physical having the dominance relation to satisfaction of patient.
\end{abstract}

Keyword; Service Quality Dimension, patient satisfaction.

\section{PENDAHULUAN}

\section{A. Latar Belakang}

Kesehatan sebagai salah satu unsur kesejahteraan umum harus diwujudkan sebagaimana dimaksud dalam pembukaan undang-undang dasar 1945 melalui pembangunan nasional yang berkesinambungan. Pembangunan kesehatan diarahkan untuk mempertinggi derajat kesehatan masyarakat sebagai bagian dari pembinaan sumber daya manusia Indonesia. Penyelenggaraan pembangunan kesehatan meliputi upaya kesehatan dan sumber dayanya yang harus dilakukan secara terpadu dan berkesinambungan guna mencapai hasil yang optimal (Rahman, Suwandi, \& Hamid, 2016).

Rumah sakit adalah salah satu bentuk organisasi pelayanan kesehatan yang merupakan bagian integral dari sistem pelayanan kesehatan yang berfungsi untuk menyelenggarakan upaya kesehatan secara komprehensif yang mencakup aspek promotif, preventif, kuratif, dan rehabilitatif.Institusi rumah sakit saat ini telah menghadapi kompetisi sehingga perlu adanya peningkatan daya saing yang berfokus pada penerapan manajemen kualitas pelayanan terpadu. Peningkatan sistem kualitas dan informasi dalam organisasi juga amat penting dalam mendorong kepuasan pelanggan institusi (Sylvana \& Awaluddin, 2017a \& b)

\footnotetext{
*Prodi Manajemen FEB Unismuh Makassar: (asdimuh@yahoo.co.id)
} 
Manajemen kualitas pelayanan terpadu pada organisasi rumah sakit telah bergesar dari paradigma lama yang berorientasi sosial menjadi industri jasa yang berorientasi ekonomi tanpa melupakan fungsi sosialnya sehingga kepuasan pasien atas pelayanan yang diberikan merupakan kunci dalam menentukan keberhasilan organisasi rumah sakit.

Pentingnya kepuasan pasien dalam organisasi rumah sakit menjadi prasyarat dalam mengembangkan kreativitas dan produktivitas pelayanan dengan terus meningkatkan sumber daya manusia pada rumah sakit secara berkesinambungan.Kualitas pelayanan ini menjadi penilaian bagi pasien dalam memperoleh pelayanan jasa kesehatan.

Rumah Sakit Umum Daerah (RSUD) Syekh Yusuf Sungguminasa Kabupaten Gowa telah mengembangkan suatu paradigma baru dalam menumbuhkan orientasi pelayanan terpadu secara kreatif dan inovatif berdasarkan standar kelayakan yang disesuaikan dengan kepuasan pasien. Pengelola RSUD Syekh Yusuf saat ini telah melakukan berbagai pembenahan dan pengembangan kualitas pelayanan, yang didukung oleh ketersediaan sarana dan fasilitas rumah sakit serta tenaga sumber daya manusia yang berjumlah 146 orang yang terdiri dari ; 26 orang dokter, 65orang perawat, 32 orang tenaga farmasi dan fungsional lainnya, serta 23 orang tenaga administrasi.

Bentuk kualitas pelayanan yang diimplementasikan oleh pengelola RSUD Syekh Yusuf adalah dimensi kualitas pelayanan yang terdiri dari bukti fisik (tangible), empati (empathy),kehandalan (realiability), keresponsipan (responsiveness), dan keyakinan (assurance) (Andrie, 2017).

\section{B. Rumusan Masalah}

1. Apakah penerapan dimensi kualitas pelayanan yang terdiri dari; bukti fisik, empati, kehandalan, keresponsipan, dan keyakinan,baik secara parsial maupun secara simultan berpengaruh terhadap kepuasan pasien pada RSUD Syekh Yusuf Sungguminasa Kabupaten Gowa?

2. Dimensi kualitas pelayanan manakah yang memberikan pengaruh dominan terhadap kepuasan pasien pada RSUD Syekh Yusuf Sungguminasa Kabupaten Gowa?

\section{TINJAUAN PUSTAKA DAN HIPOTESIS}

A. Tinjauan Pustaka

\section{Dimensi Kualitas Pelayanan}

Banyak ahli pemasaran telah berhasil mengidentifikasi dimensi kualitas pelayanan dari hasil penelitian yang dilakukannya. Diantara para peneliti tersebut ialah Stamatsi (Tjiptono, 2002 : 2005 ) yang berhasil memodifikasi delapan dimensi kualitas dari Garvin menjadi tujuh dimensi kualitas pelayanan, yaitu :

a. Fungsi (function), yaitu kinerja primer yang dituntut dari suatu pelayanan 
b. Karakteristik / ciri tambahan(features), yaitu kinerja yang diharapkan atau karakteristik pelengkap.

c. Kesesuaian (conformance), yaitu kepuasan yang didasarkan pada pemenuhan persyaratan yang telah ditetapkan.

d. Kehandalan (reliability),yaitu kepercayaan pelayanan dalam kaitan dengan waktu.

e. Dapat diperbaiki (serviceability), yaitu kemampuan untuk melakukan perbaikan apabila terjadi kekeliruan.

f. Estetika (aesthetics), yaitu pengalaman pelanggan yang berkaitan dengan perasaan dan panca indera.

g. Persepsi (perceptions), yaitu reputasi dari kualitas pelayanan.

Menurut Parasuraman (1990:26) strategi kualitas pelayanan tidak terlepas dari lima dimensi kualitas pelayanan secara berturut-turut berdasarkan penilaian kepentingan pelanggan yaitu :

a. Bukti Fisik (tangible). Bukti langsung meliputi fasilitas fisik, peralatan/perlengkapan sarana atau media komunikasi yang dimiliki oleh perusahaan.

b. Empati (empathy). Empati adalah kepedulian, ketulusan, perhatian pribadi serta berbagai kemudahan dalam komunikasi yang diberikan perusahaan dan stafnya kepada pelanggan. Termaksud pula dalam dimensi ini ialah kemampuan mengadakan pendekatan secara individual dan personal, perasaan aman dan upaya untuk memahami kebutuhan dan keinginan pelanggan.

c. Kehandalan (reliability). Kehandalan yaitu kemampuan untuk memberikan pelayanan yang telah dijanjikan dengan segera, tepat, akurat dan terpercaya. Kualitas pelayanan yang handal merupakan harapan pelanggan yang berarti bahwa pelayanan tersebut setiap saat dituntut untuk dapat dilaksanakan dengan segera, tepat waktu, dengan cara yang sama dan tanpa kesalahan.

d. Keresponsipan (responsiveness). Keresponsipan merupakan keinginan untuk membantu para pelanggan dan memberikan pelayanan dengan tanggap, cepat dan tepat. Keresponsipan berpengaruh terhadap kualitas pelayanan. Pelanggan yang terpaksa harus menunggu lama untuk mendapatkan pelayanan tanpa alasan yang jelas akan menimbulkan persepsi negatif terhadap kualitas pelayanan.

e. Keyakinan (asurance). Jaminan disini meliputi pengetahuan, kemampuan dan kesopanan staf yang dapat menimbulkan kepercayaan dan keyakinan dari para pelanggan kepada perusahaan. Dimensi ini meliputi kompetensi / kemampuan dalam pemberian pelayanan, kesopanan dan rasa hormat kepada pelanggan, sifat dapat dipercaya, jaminan rasa aman dari bahaya, resiko atau keraguraguan serta komunikasi yang efektif dengan pelanggan. 
Lima dimensi kualitas pelayanan diatas, banyak digunakan oleh para ahli dalam menjelaskan kualitas pelayanan. Berdasarkan lima dimensi tersebut, para pelanggan mengevaluasi kualitas pelayanan dengan cara membandingkan pelayanan yang diharapkan dan pelayanan yang dirasakannya. Kesenjangan antara pelayanan yang diharapkan dengan yang dirasakan untuk setiap dimensi merupakan ukuran kualitas pelayanan berdasarkan persepsi pelanggan.

\section{Kepuasan Pelanggan}

Menurut Engel (1990:23) kepuasan adalah perasaan senang atau kecewa seseorang yang berasal dari perbandingan antara kesannya terhadap hasil suatu produk dan harapan-harapannya. Kepuasan merupakan fungsi dari kesan kinerja dan harapan. Jika kinerja berada dibawah harapan, pelanggan akan tidak puas, dan jika kinerja melebihi harapan, maka pelanggan akan merasa puas. Dalam kaitan itu, maka faktor kepuasan pelanggan (customer satisfaction) menjadi elemen penting dalam memberikan atau menambah nilai bagi pelanggan

Konsep dan teori mengenai kepuasan konsumen telah berkembang pesat dan telah mampu diklasifikasikan atas beberapa pendekatan.Salah satu pendekatan yang paling populer yang berhubungan dengan kepuasan konsumen adalah teori The Expectancy Disconfirmation Model.

Teori ini menekankan bahwa kepuasan atau ketidak puasan ditentukan oleh suatu proses evaluasi konsumen, dimana persepsi konsumen mengenai suatu produk atau jasa dibandingkan dengan standar yang diharapkan. Proses inilah yang disebut dengan proses diskonfirmasi.

Menurut Rangkuti (2003:40) kepuasan pelanggan terhadap suatu jasa ditentukan oleh tingkat kepentingan pelanggan sebelum menggunakan jasa dibandingkan dengan hasil persepsi pelanggan terhadap jasa tersebut setelah pelanggan merasakan kinerja jasa tersebut.

Salah satu faktor yang menentukan kepuasan pelanggan adalah kualitas pelayanan yang terdiri dari lima dimensi pelayanan. Kesenjangan merupakan ketidaksesuaian antara pelayanan yang dipersepsikan (perceived service) dan pelayanan yang diharapkan (expected service).Jika pelayanan yang dipersepsikan lebih tinggi dari yang diharapkan maka pelanggan merasakan sangat puas, dan sebaliknya jika pelayanan lebih rendah dari yang diharapkan maka pelanggan merasakan tidak puas atau kecewa (Saleky, 2017).

\section{B. Hipotesis}

1. Penerapan dimensi kualitas pelayanan yang terdiri dari ; bukti fisik, empati, kehandalan, korespensipan, dan keyakinan, baik secara parsial maupun secara simultan berpengaruh terhadap kepuasan pasien pada RSUD Syekh Yusuf Sungguminasa Kabupaten Gowa. 
2. Bukti fisik adalah dimensi kualitas pelayanan yang memberikan pengaruh dominan terhadap kepuasan pasien pada RSUD Syekh Yusuf Sungguminasa Kabupaten Gowa.

\section{METODE PENELITIAN}

Penelitian ini dilaksanakan di RSUD Syekh Yusuf Sungguminasa Kabupaten Gowa pada bulan April dan Mei 2016.Tehnik pengumpulan data yang digunakan adalah dokumentasi, wawancara, observasi dan kuesioner sebagai metode utama untuk mendapatkan data primer dari para responden.

Populasi ditentukan dari angka rata-rata pasien perbulan yaitu 2.997 pasien, sedangkan besarnya sampel ditetapkan $10 \%$ dari populasi yaitu 300 pasien yang terdiri dari 250 pasien rawat-jalan dan 50 pasien rawat-inap.

Karateristik responden diperoleh dengan menggunakan tehnik analisis persentase, sedangkan pengujian hipotesis menggunakan teknik analisis Koefisien Kontingensi (C), Koefisien Phi $(\Theta)$, dan Koefisien Determinasi(KP).

\section{HASIL PENELITIAN DAN PEMBAHASAN}

\section{A. Hasil Penelitian}

\section{Deskripsi Karakteristik Responden}

a. Jenis kelamin ; responden laki-laki 266 pasien ( 88,7 \%), dan responden perempuan 34 pasien $(11,3 \%)$

b. Umur ; responden umur 21 - 25 tahun 49 pasien (16,3\%), umur $26-30$ tahun 106 pasien ( $35,3 \%)$, umur $31-35$ tahun 56 pasien (18,7\%) umur 36 - 40 tahun 73 pasien $(24,3 \%)$, dan $>41$ tahun 16 pasien $(5,3 \%)$.

\section{Diskripsi Variabel Penelitian}

\section{a. Variabel Kepuasan Pasien}

Frekwensi kepuasan pasien terlihat pada tabel 1 berikut :

Tabel 1 Frekwensi Tingkat Kepuasan Pasien

\begin{tabular}{|c|c|c|c|c|}
\hline \multicolumn{5}{|c|}{ Frekwensi Tingkat Kepuasan Pasien } \\
\hline $\begin{array}{c}\text { Sangat } \\
\text { Puas }\end{array}$ & Puas & $\begin{array}{c}\text { Cukup } \\
\text { Puas }\end{array}$ & $\begin{array}{c}\text { Kurang } \\
\text { Puas }\end{array}$ & $\begin{array}{c}\text { Tidak } \\
\text { Puas }\end{array}$ \\
\hline 97 & 25 & 118 & 31 & 29 \\
\hline
\end{tabular}

Sumber : Hasil Penelitian, 2016

b. Variabel Dimensi Kualitas Pelayanan

Frekwensi pasien tiap-tiap dimensi kualitas pelayanan terlihat pada tabel 2 berikut : 
Tabel 2 : Frekwensi Tiap Kategori Dimensi Kualitas Pelayanan

\begin{tabular}{|l|c|c|c|c|c|}
\hline \multirow{2}{*}{$\begin{array}{c}\text { Dimensi } \\
\text { Kualitas } \\
\text { Pelayanan }\end{array}$} & \multicolumn{5}{|c|}{ Frekwensi Pasien Tiap Kategori } \\
\cline { 2 - 6 } & $\begin{array}{c}\text { Sangat } \\
\text { Sesuai }\end{array}$ & Sesuai & $\begin{array}{c}\text { Cukup } \\
\text { Sesuai }\end{array}$ & $\begin{array}{c}\text { Kurang } \\
\text { Sesuai }\end{array}$ & $\begin{array}{c}\text { Tidak } \\
\text { Sesuai }\end{array}$ \\
\hline Bukti Fisik & 29 & 135 & 61 & 44 & 31 \\
\hline Empati & 39 & 60 & 141 & 28 & 32 \\
\hline Kehandalan & 85 & 105 & 35 & 38 & 37 \\
\hline Keresponsipan & 95 & 88 & 68 & 42 & 7 \\
\hline Keyakinan & 33 & 77 & 98 & 62 & 10 \\
\hline Jumlah & 281 & 465 & 403 & 214 & 137 \\
\hline
\end{tabular}

Sumber : Hasil Penelitian, 2016

\section{Deskripsi Hasil Analisis Hubungan Antar Variabel}

Tabel 3 :Hubungan Dimensi Kualitas Pelayanan Dengan Kepuasan Pasien

\begin{tabular}{|c|c|c|c|c|c|}
\hline $\begin{array}{c}\text { Dimensi } \\
\text { Kualitas } \\
\text { Pelayanan }\end{array}$ & $\mathbf{X}^{\mathbf{2}}$ & $\mathbf{C}$ & $\mathbf{P h i} \mathbf{( \Theta )}$ & $\begin{array}{c}\text { Indeks } \\
\text { Korelasi }\end{array}$ & KP \\
\hline Bukti Fisik & 98,924 & 0,498 & $0,574^{*}$ & $\begin{array}{c}\text { Cukup } \\
\text { Kuat }\end{array}$ & 0,329 \\
\hline Empati & 65,902 & 0,424 & $0,468^{*}$ & $\begin{array}{c}\text { Cukup } \\
\text { Kuat }\end{array}$ & 0,219 \\
\hline Kehandalan & 79,148 & 0,457 & $0,514^{*}$ & $\begin{array}{c}\text { Cukup } \\
\text { Kuat }\end{array}$ & 0,264 \\
\hline Keresponsipan & 89,181 & 0,479 & $0,546^{*}$ & $\begin{array}{c}\text { Cukup } \\
\text { Kuat }\end{array}$ & 0,298 \\
\hline Keyakinan & 59,901 & 0,407 & $0,446^{*}$ & $\begin{array}{c}\text { Cukup } \\
\text { Kuat }\end{array}$ & 0,199 \\
\hline $\begin{array}{c}\text { Secara } \\
\text { Simultan }\end{array}$ & 220,714 & 0,651 & $0,858^{*}$ & $\begin{array}{c}\text { Sangat } \\
\text { Kuat }\end{array}$ & 0,736 \\
\hline \multicolumn{2}{|l|}{ Signifikant : ts $1 \%=\geq 0,148, *=$ Signifikant } \\
\hline
\end{tabular}

Sumber : Data diolah, 2016

Hasil analisis data pada tabel 3 menunjukkan bahwa antara variabel dimensi kualitas pelayanan yang terdiri dari bukit fisik, empati, kehandalan, koresponsipan dan keyakinan dengan variabel kepuasan pasien adalah signifikant berkorelasi cukup kuat. 


\section{B. Pembahasan}

\section{Bukti Fisik terhadap Kepuasan Pasien}

Pengaruh dimensi bukti fisik terhadap kepuasan pasien ditandai dengan koefisien phi sebesar 0,574 atau korelasi cukup kuat, ditandai pula dengan koefisien determinasi sebesar 0,329 berarti berpengaruh sebesar 32,9 \%. Hal demikian menunjukkan bahwa dalam penerapannya, dimensi bukti fisik dalam kualitas pelayanan memiliki pengaruh signifikan terhadap kepuasan pasien.

\section{Empati terhadap Kepuasan Pasien}

Pengaruh dimensi empati terhadap kepuasan pasien ditandai dengan koefisien phi sebesar 0,468 atau korelasi cukup kuat, ditandai pula dengan koefisien determinasi sebesar 0,219 berarti berpengaruh sebesar 21,9\%. Hal demikian menunjukkan bahwa dalam penerapannya, dimensi empati dalam kualitas pelayanan berpengaruh signifikan terhadap kepuasan pasien.

\section{Kehandalan terhadap Kepuasan Pasien}

Pengaruh dimensi kehandalan terhadap kepuasan pasien ditandai dengan koefisien phi sebesar 0,514 atau korelasi cukup kuat, ditandai pula dengan koefisien determinasi sebesar 0,264 berarti berpengaruh sebesar 26,4 \%. Hal demikian menunjukkan bahwa dalam penerapannya, dimensi kehandalan dalam kualitas pelayanan berpengaruh signifikan terhadap kepuasan pasien.

\section{Keresponsipan terhadap Kepuasan Pasien}

Pengaruh dimensi keresponsipan terhadap kepuasan pasien ditandai dengan koefisien phi sebesar 0,546 atau korelasi cukup kuat, ditandai pula dengan koefisien determinasi sebesar 0,298 berarti berpengaruh sebesar 29,8 \%. Hal demikian menunjukkan bahwa dalam penerapannya, dimensi keresponsipan dalam kualitas pelayanan berpengaruh signifikanterhadap kepuasan pasien.

\section{Keyakinan terhadap Kepuasan Pasien.}

Pengaruh dimensi keyakinan terhadap kepuasan pasien ditandai dengan koefisien phi sebesar 0,446 atau korelasi cukup kuat, ditandai pula dengan koefisien determinasi sebesar 0,199 berarti berpengaruh sebesar 19,9\%. Hal demikian menunjukkan bahwa dalam penerapannya, dimensi keyakinan dalam kualitas pelayanan berpengaruh signifikan terhadap kepuasan pasien.

\section{Secara simultan Kualitas Pelayananterhadap Kepuasan Pasien}


Secara simultan pengaruhdimensi kulalitas pelayanan terhadap kepuasan pasien ditandai dengan koefisien phi sebesar 0,858 atau korelasi sangat kuat, ditandai pula dengan koefisien determinasi sebesar 0,736 berarti berpengaruh sebesar 73,6 \%. Hal demikian menunjukkan bahwa secara simultan dimensi kualitas pelayanan yang terdiri dari ;bukti fisik, empati, kehandalan, keresponsipan, dan keyakinan,berpengaruh signifikan terhadap kepuasan pasien.

\section{SIMPULAN DAN SARAN}

\section{A. Simpulan}

1. Baik secara simultan maupun secara parsial dimensi kualitas pelayanan yang terdiri dari ; bukti fisik, empati, kehandalan, keresponsipan, dan keyakinan berpengaruh signifikan (73,6 \%) terhadap kepuasan pasien pada RSUD Syekh Yusuf Sungguminasa Kabupaten Gowa

2. Dimensi bukti fisik dalam kualitas pelayanan berpengaruh dominan $(32,9 \%)$ terhadap kepuasan pasien karena memiliki nilai koefisien kontingensi, koefisien phi dankoefisien determinasi yang tertinggi dibandingkan dengan dimensi kualitas pelayanan lainnya.

\section{B. Saran}

1. Agar pihak manajemen RSUD Syekh Yusuf Sungguminasa Kabupaten Gowa dapat merumuskan strategi operasional peningkatan kualitas pelayanan yang disesuaikan dengan harapan dan keinginan pasien

2. Agar pihak manajemen RSUD Syekh Yusuf Sungguminasa Kabupaten Gowa perlu merumuskan suatu sistem penilaian tentang dimensi kualitas pelayan terhadap pasien yang dilakukan secara berkala dan berkesinambungan.

\section{DAFTAR PUSTAKA}

Andrie, S. C. (2017). Pengaruh Kualitas Layanan dan Kepuasan Pasien terhadap Words of Mouth pada Rumah Sakit Umum Daerah dr. M. Haulussy Ambon. Jurnal Manajemen Ide dan Inspirasi, 4(01).

Engel, James, 1990, Satisfaction, A.Behavioral Perspective On The Consumer, Mc Graw Hill Companies Inc, USA

Hamzenah, Gaffur, 2003. Pemasaran Jasa dalam Tinjaun Bisnis. Sinar Baru, Bandung. Lupiyoadi, Rambat, 2001. Manajemen Pemasaran Jasa, Teori dan Praktek. Salemba Empat, Jakarta.

Parasuraman, A.Valerie. 1990, Delivering Quality Service. The Free Press New York.

Rahman, M. A., Suwandi, M., \& Hamid, A. (2016). TRANSPARANSI DAN AKUNTABILITAS PENGELOLAAN KEUANGAN ALOKASI DANA DESA (ADD) DALAM PENCAPAIAN GOOD GOVERNANCE (Studi Empiris di Kecamatan Bontomarannu Kabupaten Gowa). Jurnal Manajemen Ide dan Inspirasi, 3(2). 
Rangkuti, Freddy, 2003.Konsep Pengukuran Kepuasan Pelanggan. PT. Gramedia Pustaka Utama, Jakarta

Saleky, S. R. J. (2017). Anteseden Loyalitas Pelanggan Domestik Garuda Indonesia Di Kota Ambon. Jurnal Manajemen Ide dan Inspirasi, 4(01).

Sylvana, A., \& Awaluddin, M. OPTIMIZATION OF ONLINE TUTOR SATISFACTION THROUGH IMPROVEMENT OF QUALITY SYSTEMS, INFORMATION QUALITY AND IMPROVEMENT OF CONTACT PERSONNEL SERVICES AT UNIVERSITAS TERBUKA. QUALITY ASSURANCE IN OPEN UNIVERSITY, 95.

Sylvana, A., \& Awaluddin, M. STUDENT SATISFACTION ANALYSIS OF ONLINE TUTORIAL THROUGH INFORMATION SYSTEM QUALITY AND PERSONAL SERVICES OF ONLINE TUTORIAL AT UNIVERSITAS TERBUKA. QUALITY ASSURANCE IN OPEN UNIVERSITY, 88.

Tjiptono, Fandy, 2002. Strategi Pemasaran dan Kualitas Pelayanan.Andi, Yogyakarta.

Yazid, 1999.Pemasaran Jasa Konsep dan Implementasi Ekonisa Fakultas Ekonomi UII Yogyakarta. 


\title{
Penanggung Jawab \\ Ambo Asse
}

\section{Ketua/}

M. Wahyuddin Abdullah

\author{
Dewan Editor \\ Alim Syariati \\ Rusdi Prayoga \\ Andi Mulia \\ Rusnawati
}

\author{
Mitra Bestari/Reviewer \\ Ambo Asse (UIN Alauddin Makassar), \\ Firman Menne (Universitas Bosowa Makassar) \\ Suwandi Ng (Universitas Atma Jaya Makassar), \\ Agus Salim (ISEI Sul-Sel), \\ Rika Dwi Ayu Parmitasari (UIN Alauddin Makassar), \\ Ahmad Efendi (UIN Alauddin Makassar), \\ Awaluddin (UIN Alauddin Makassar), \\ Okta Nofri (UIN Alauddin Makassar), \\ Eka Suhartini (UIN Alauddin Makassar), \\ Akil Rahman (UIN Alauddin Makassar),
}

\author{
Sekretaris Penyunting \\ Rusmawandi Rara \\ Nurhikma Hawabaja \\ Roshani
}

\author{
JURNAL MINDS \\ Pusat Dokumentasi dan Publikasi IImiah \\ Jurusan Manajemen Fakultas Ekonomi dan Bisnis Islam UIN Alauddin \\ JI. Sultan Alauddin No. 33 Samata-Gowa Sul-Sel -- INDONESIA \\ Telp/HP. 081355774774, 081241840208, Fax. (0411) 8221400 \\ Website OJS: http://journal.uin-alauddin.ac.id/index.php/minds \\ Email: minds@uin-alauddin.ac.id
}




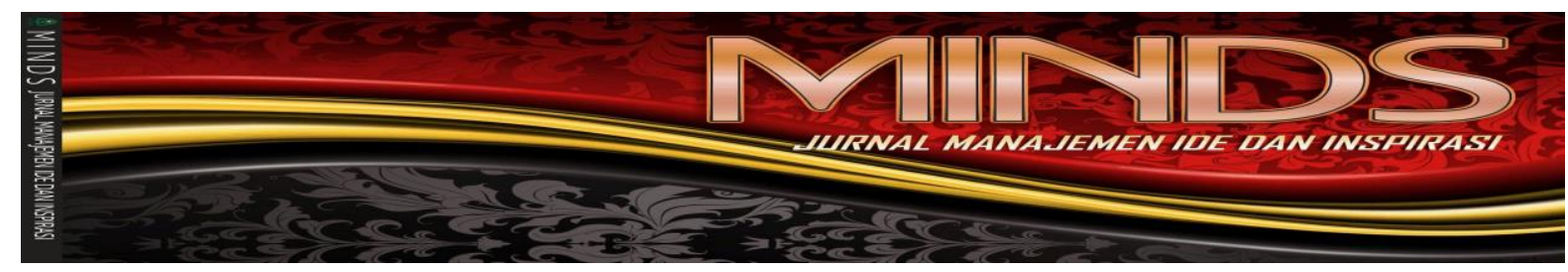

\section{KRITERIA TULISAN}

1. Panjang tulisan minimal 10 halaman dan maksimal 15 halaman

2. Menggunakan huruf Book Antiqua, font 12 , spasi 1, margin atas-bawah $3 \mathrm{~cm}$, kiri-kanan $2.54 \mathrm{~cm}$.

3. Tulisan dapat berupa hasil penelitian kuantitatif (diutamakan), penelitian kualitatitif, dan kajian teoritis dalam bidang Manajemen dengan penguatan pada integrasi keislaman.

4. Identitas penulis meliputi: nama penulis tanpa gelar, nama dan alamat afiliasi, dan alamat email penulis (contoh Alim Syariati, Fakultas Ekonomi dan Bisnis Islam UIN Alauddin, JI. HM. Yasin Limpo, NO. 63 Samata-Gowa, alim.syariati@uin-alauddin.ac.id).

5. Komposisi tulisan harus mengikuti pola berikut:

a. Judul

b. Abstrak (bahasa Indonesia dan bahasa Inggris) maksimal 150 kata dan kata kunci 3-5 kata

c. Pendahuluan (Yang didalamnya menyinggung mengenai masalah penelitian)

d. Tinjauan teoritis

e. Metode penelitian

f. Pembahasan

g. Penutup

h. Daftar pustaka

Buku: Hartono, Jogiyanto, 2004. Metodologi Penelitian Bisnis: Salah Kaprah dan pengalaman-pengalaman. Edisi 2004/2005. BPFE, Yogyakarta

Jurnal: Barney, Jay B. 1995. Looking Inside Competitive Advantage. Academy of Management, pp. 49-61

Penelitian Tidak Publikasi: Minimal sumber referensi berasal dari disertasi S3 (tapi tidak dianjurkan), dengan mengikuti format di atas

6. Menggunakan Innote

7. Waktu penting dalam penerbitan Jurnal berkala IImiah Minds, yaitu bulan Maret- Mei untuk terbitan pertama tahun berjalan, dan Oktober-November untuk terbitan kedua tahun berjalan melalui online journal system (OJS) yang bisa diakses melalui laman http://journal.uin-alauddin.ac.id/index.php/minds. Pertanyaan terkait jurnal Minds bisa disampaikan melalui email: minds@uin-alauddin.ac.id atau alim.syariati@uinalauddin.ac.id 